\title{
Analisis Sistem Pengelolaan Limbah B3 Di Industri Tekstil Kabupaten Bandung
}

\author{
Eka Wardhani, Dea Salsabila \\ Teknik Lingkungan Fakultas Teknik Sipil dan Perencanaan Institut Teknologi Nasional \\ Bandung Jalan PHH Mustofa No 23 Bandung 40124 \\ E-mail: ekawardhani08@gmail.com,9f.deasalsabila@gmail.com
}

Received 07 Agustus 2020| Revised 08 September 2020| Accepted 30 December 2021

\begin{abstract}
ABSTRAK
Penelitian ini bertujuan untuk mengetahui pengelolaan LB3 yang telah dilakukan di indsutri tekstil. Metode penelitian menggunakan metode perbandingan antara kondisi di lapangan dengan peraturan yang berlaku. Berdasarkan hasil evaluasi mengenai pengelolaan LB3 yang dilakukan oleh PT X dapat disimpulkan beberapa hal yaitu sumber LB3 berasal dari proses produksi, lumpur IPAL, boiler, labolatorium, pemeliharaan mesin, dan klinik. Jenis LB3 yang dihasilkan berasal dari sumber spesifik umum yaitu lumpur IPAL dan limbah medis, sumber spesifik khusus yaitu hanya fly ash dan sumber tidak spesifik yang meliputi lampu TL, drum bekas LB3, oli bekas dan reagen. Karakteristik LB3 terdiri dari beracun, mudah menyala, korosif dan infeksius. PT X telah melakukan pengelolaan LB3 yang meliputi aspek pengemasan dan pewadahan, pengumpulan, penyimpanan, pengangkutan dokumen pengelolaan LB3, dan pelabelan LB3. Untuk kegiatan pengangkutan PT X bekerja sama dengan pihak ketiga diantaranya adalah PT Hijau Lestari, PT PPLI, PT Khalda, dan WGI. Berdasarkan hasil analisis pengelolaan LB3 di perusahaan ini termasuk kategori baik. Upaya pengelolaan LB3 yang harus ditingkatkan yaitu pada proses pelekatan simbol dan label, pengemasan, dan penyimpanan LB3.
\end{abstract}

Kata Kunci: Kabupaten Bandung, Industri Tekstil, Limbah B3,

\begin{abstract}
This study aims to determine the management of LB3 that has been carried out in the textile industry. The research method uses a comparison between conditions in the field and applicable regulations Based on the evaluation results on the management of hazardous materials carried out by PT X, it can be concluded several things, namely the source of hazardous materials originating from the production process, sludge from the wastewater treatment plant, boilers, laboratory, engine maintenance, and clinics. The types of hazardous materials produced come from general specific sources such are sludge from the wastewater treatment plant and medical waste, specific sources which are fly ash and non-specific sources which include lamps, drums used in hazardous materials, used oil and reagents. The characteristics of hazardous materials consist of toxic, flammable, corrosive, and infectious. PT X has managed the management of hazardous materials which includes aspects of packaging, storage, collection, storage, transportation of documents on the management of hazardous materials, and labeling of hazardous materials. For transportation activities, PT X cooperates with third parties including PT Hijau Lestari, PT PPLI, PT Khalda, and WGI. Based on the analysis the achievement of the management of dangerous substances in this company including the good category. Efforts to manage toxic and hazardous materials must be improved in the process of sticking symbols and labels, packaging, and storing toxic and hazardous materials.
\end{abstract}

Keywords: Bandung Regency, Testile iIndustry, hazardous waste materials 


\section{PENDAHULUAN}

Kebutuhan manusia akan sandang terus mengalami peningkatan seiring dengan pertambahan penduduk. Hal tersebut menyebabkan pertumbuhan industri tekstil terus mengalami perkembangan. Pabrik tekstil menghasilkan benang, kain hingga pakaian jadi (garmen). Proses produksinya berpotensi menghasilkan limbah dalam bentuk padat, cair, dan gas, diantara limbah yang ditimbulkan ada yang bersifat bahan berbahaya dan beracun (B3) [1]. Berdasarkan Peraturan Pemerintah Republik Indonesia (PPRI) No. 101 tahun 2014 tentang pengelolaan limbah B3 (LB3), limbah ini merupakan sisa suatu usaha dan/atau kegiatan yang mengandung B3. Limbah dikatagorikan B3 jika memiliki sifat mudah meledak (explosive), pengoksidasi (oxidizing), mudah menyala (flammable), beracun (moderately toxic), berbahaya (harmful), korosif (corrosive), bersifat iritasi (irritant), berbahaya bagi lingkungan (dangerous to the environment), karsinogenik (carcinogenic), teratogenik (teratogenic), mutagenik (mutagenic) [2]. Limbah tersebut harus dikelola dengan baik supaya tidak menimbulkan dampak negatif bagi kesehatan pekerja serta masyarakat yang berada di sekitar pabrik tekstil tersebut.

Pabrik tekstil PT X merupakan perusahaan nasional berlokasi di Dayeuhkolot Kabupaten Bandung. Perusahaan ini memiliki bagian proses penenunan kain, pemintalan, serta pencelupan. Kapasitas produksinya mencapai 3 juta yard/bulan dengan konsumen terdiri dari distributor tekstil, industri garmen, dan pengolah produk tekstil dalam dan luar negeri. Produk yang dibuat adalah produk benang (twisting), tenun (woven/greige), rajut (knitting), dan produk penyempurnaan (celup dan printing) (Profil PT X, 2019). Proses yang dilakukan di industri tersebut menggunakan bahan kimia yang dapat dikategorikan sebagai $\mathrm{B} 3$ seperti pewarna tekstil, $\mathrm{NaOH}$, dan bahan kimia lainnya supaya dihasilkan kain yang sesuai dengan persyaratan konsumen [1].

Sifatnya yang berbahaya terhadap kesehatan manusia dan lingkungan maka LB3 yang dihasilkan harus ditangani dengan baik. Pengelolaan LB3 harus mengacu kepada peraturan yang berlaku mulai dari proses penyimpanan, pengumpulan, pemanfaatan, pengangkutan dan pengelolaan termasuk penimbunan. Penanganan LB3 yang baik akan mampu mengurangi timbulan limbah yang dihasilkan sehingga dapat mencegah terjadinya pencemaran lingkungan. Maksud penelitian ini adalah melakukan evaluasi terhadap sistem pengelolaan LB3 di PT X. Tujuan dari penelitian ini yaitu mengidentifikasi sumber dan karakteristik limbah B3, menghitung timbulan LB3 yang dihasilkan, serta melakukan evaluasi terhadap sistem pengelolaan LB3.

Pengelolaan LB3 di Indonesia telah diatur secara lengkap, sehingga penelitian ini mengacu kepada peraturan yang berlaku diantaranya yaitu: (a) Peraturan Pemerintah Republik Indonesia (PPRI) No. 101 Tahun 2014 tentang Pengelolaan LB3 [3], (b) Peraturan Menteri Lingkungan Hidup (Permen LH) No. 14 Tahun 2013 tentang simbol dan label LB3 [4], (c) Keputusan Badan Pengendalian Dampak Lingkungan (Bapedal) No. 1 Tahun 1995 tentang penyimpanan dan pengumpulan LB3 [5], (d) Keputusan Bapedal No. 2 Tahun 1995 tentang dokumen LB3 [6].

\section{METODE PENELITIAN}

Penelitian diawali dengan studi pustaka mengenai pengelolaan LB3 terutama di industri tekstil. Literatur yang dipelajari meliputi proses produksi tekstil, LB3 yang dihasilkan, metode pewadahan, pengangkutan serta pengelolaannya. Hal lain terkait penelitian dipelajari untuk membantu dalam analisis data. Pengumpulan data merupakan langkah kedua yang dilaksanakan. Data yang dikumpulkan terdiri atas data primer dan sekunder. Wawancara dan pengamatan di PT X dilakukan untuk memperoleh data primer sedangkan data sekunder meliputi profil perusahaan, proses produksi, LB3 yang dihasilkan, bentuk pengelolaannya diperoleh dari data yang diberikan oleh PT X.

Pengolahan data dilakukan dengan menggunakan metode komparasi antara pengelolaan LB3 eksisting di PT X dengan peraturan mengenai pengelolaan LB3 yang berlaku di Indonesia. Hasil komparasi tersebut dilakukan pembobotan dengan menggunakan Skala Guttman. Skala ini disebut juga skala scalogram merupakan metode yang sangat baik untuk meyakinkan hasil penelitian mengenai kesatuan 
dimensi dan sifat yang diteliti yakni sesuai dan tidak sesuai [7]. Nilai perhitungan pembobotan menggunakan skala Guttman ini jika hasil komparasi sesuai maka diberi nilai 1 sebaliknya jika tidak sesuai diberi nilai 0 . Pemberian nilai dilakukan antara peneliti dengan pihak perusahaan dengan tujuan untuk mencapai kesamaan persepsi. Hasil dari pembobotan dengan skala Guttman kemudian dilakukan perhitungan terhadap persentasi skoring, dengan rumus yang disajikan pada persamaan (1). Pemakaian skala ini untuk menilai pengelolaan LB3 telah banyak dipergunakan oleh penelitian lain $[8,9,10]$ Persentase skor yang telah diperoleh ditentukan kategori penilaiannya dengan mengacu kepada Tabel 1 .

Persentase skoring $=\frac{\text { Score total eksisting }}{\text { Score total ideal }} \times 100 \% \ldots \ldots \ldots \ldots \ldots$
\begin{tabular}{cc} 
Tabel 1. Kategori penilaian pengelolaan LB3 \\
\hline Nilai (\%) & Kategori \\
\hline $81-100$ & Baik sekali \\
\hline $61-80$ & Baik \\
\hline $41-60$ & Cukup \\
\hline $21-40$ & Buruk \\
\hline $0-20$ & Buruk Sekali
\end{tabular}

Sumber: [7]

\section{HASIL DAN PEMBAHASAN}

Produk yang dihasilkan oleh PT X berupa gulungan benang, kain geige, dan juga kain jadi. Proses produksi di pabrik tekstil PT X terdiri dari dua proses utama yaitu penenunan dan pencelupan [1]. Proses penenunan benang dilakukan seperti menganyam yaitu dengan cara menyilang benang sehingga dihasilkan kain. Alur kerja dari proses tenun terdiri atas:

1. Proses menggulung benang lusi dengan arah sejajar pada beam dengan panjang tertentu. Proses ini merupakan salah satu diantara sekian proses persiapan penenunan.

2. Proses pengkanjian, pada proses ini benang-benang lusi dikanji yang sebelumnya sudah melewati proses penggulungan benang. Proses ini melapisi benang lusi dengan kanji supaya benang-benang lusi kuat dan tahan gesek, karena setelah proses penganjian ini benang lusi akan di cucuk dan setelah pencucukan akan di tenun.

3. Proses pemisahan benang atas dan benang bawah menggunakan mesin.

4. Proses cucuk merupakan proses memasukkan tiap-tiap benang lusi pada lubang dropper yang ada pada masing-masing gun serta sisir tenun yang sesuai dengan rencana desain kain tenun yang akan dibuat yang selanjutnya dicucuk pada lubang kain sisir. Proses pemasukan benang lusi pada lubang dropper, mata gun, dan sisir dapat dilakukan dengan dua cara yaitu dengan cara manual menggunakan tangan dan dengan menggunakan mesin cucuk. Proses mencucuk akan mempengaruhi jenis anyaman yang akan dibuat.

5. Tenun adalah proses pembuatan kain dari persilangan dua set benang dengan cara memasukmasukkan benang secara melintang pada benang-benang lusi atau proses pembuatan kain yang berasal dari benang yang disilang seperti halnya anyaman.

Proses pencelupan merupakan pewarnaan merata pada kain dengan alur kerja sebagai berikut:

Bahan baku yang digunakan pada proses ini adalah kain greige hasil proses penenunan. Kain tersebut adalah kain setengah jadi hasil produksi dari bagian penenunan untuk diwarnai sehingga menjadi kain jadi atau kain yang siap untuk di jahit. Proses awal pencelupan yaitu persiapan, proses ini bertujuan agar kain sebelum dilakukan proses celup dan pencapan ada dalam kondisi bersih baik dari kotoran. Proses persiapan ini meliputi:

$\checkmark$ Singeing (membakar bulu pada kain) dengan tujuan untuk menghilangkan bulu yang ada pada kain sehingga tidak mengganggu proses berikutnya. Kain yang telah dibakar harus memenuhi persyaratan yaitu (1) bulu kain telah hilang (rata) pada semua bagian permukaan kain, (2) kain tidak boleh ada yang hangus atau terbakar, dan (3) kain tidak boleh cacat karena proses bakar bulu. 
$\checkmark$ Desizing (proses pembuangan kanji) dengan tujuan membersihkan kain dari kanji yang ditambahkan pada proses penenunan. Kandungan kanji dalam kain dapat menghalangi daya serap kain terhadap zat warna.

$\checkmark$ Scouring (pemasakan) tujuan dari proses ini yaitu menghilangkan kotoran (lemak, lilin, pectin, $\mathrm{dsb}$ ) agar tidak mengganggu proses penyerapan selanjutnya.

$\checkmark$ Merseriasi tujuan dari proses ini adalah menambah kekuatan serat kain, membuat sejajar rantai molekul serat kain, dan menambah daya serap serat kain terhadap zat warna. Proses dilakukan dengan menggunakan larutan $\mathrm{NaOH}$ dengan konsentrasi yang cukup tinggi dengan temperatur dingin sekitar $18^{\circ} \mathrm{C}$. Proses selanjutnya yaitu pencucian dan netralisasi.

$\checkmark$ Bleaching (pengelantangan) tujuan dari proses ini adalah menghilangkan pigmen alam/pewarna yang terdapat dalam serat kain. Prosesnya dilakukan secara oksidasi atau reduksi sehingga pigmen alam terurai menjadi tidak berwarna.

$\checkmark$ Heat Setting (pemantapan panas) tujuan proses ini adalah menambah stabilitas dimensi, terutama untuk bahan poliester atau campurannya dengan serat selulosa (kapas atau rayon). Bahan diregangkan/ditarik dan dipananskan pada suhu sedikit di bawah titik lelehnya, sehingga molekul serat menjadi lebih sejajar dan stabil.

$\checkmark$ Weight Reduce (pengurangan berat) tujuan dari proses ini adalah untuk mengurangi berat dengan cara pengikisan kain agar diperoleh pegangan kain yang empuk. Proses ini biasa di lakukan pada kain polyester. Zat yang dipergunakan untuk pengurangan berat adalah larutan $\mathrm{NaOH}$.

Proses pencelupan merupakan proses pemberian warna secara merata pada permukaaan kain secara menyeluruh. Finishing merupakan proses akhir setelah pencelupan dan atau pencapan. Cara yang digunakan pada proses ini adalah kimia dan mekanik atau gabungan keduanya disesuaikan dengan tujuan akhir proses penyempurnaan; Dry Finish (penyempurnaan kering) dan Wet Finish (penyempurnaan basah) [1].

Selain menghasilkan produk, setiap proses juga menghasilkan limbah baik cair maupun padat yang bersifat B3 dan non B3. Limbah yang dihasilkan dikumpulkan di tiap departemen. Sampah non B3 yang bersumber dari perkantoran seperti kertas dan tissue bekas setelah dikumpulkan di setiap departemen kemudian diangkut menuju tempat pembakaran sampah yang letaknya di dalam PT X. Abu dari hasil pembakaran sampah non B3 akan dikumpulkan di dalam drum untuk kemudian disimpan di TPS. Limbah cair yang dihasilkan disalurkan ke instalasi pengolahan air limbah (IPAL) untuk diolah sebelum dibuang ke badan air penerima.

Berdasarkan hasil pengamatan, LB3 (Limbah bahan beracun dan berbahaya) yang dihasilkan bersumber dari proses produksi, boiler, labolatorium, IPAL, dan klinik. Perhitungan jenis, kode kategori bahaya, dan timbulan LB3 yang dihasilkan PT X disajikan pada Tabel 2. Berdasarkan kategori bahanyanya sesuai dengan PPRI No 101 tahun 2014 LB3 dibagi menjadi dua katagori. Kategori 1, memiliki dampak langsung terhadap kesehatan manusia/dampak akut seperti bahan baku yang rusak/tumpah, produk yang tumpah, sisa produk ruahan yang tidak dapat digunakan kembali dalam proses produksi, sisa hasil pengujian produk antara, ruahan, stabilitas dan lain-lain, dan produk kembalian. Kategori 2, memiliki dampak secara tidak langsung terhadap kesehatan manusia/dampak kronis seperti majun dan bekas oli, kertas saring sisa pengujian, bahan kemas primer dan lumpur dari IPAL. Berdasarkan peraturan yang sama sumbernya LB3 dibagi menjadi sumber spesifik dan suber tidak spesifik.

PT X rata-rata menghasilkan lumpur IPAL sebanyak $21.490 \mathrm{~kg} / \mathrm{bulan}$ lumpur ini mengandung banyak bahan kimia yang dapat membahayakan kesehatan dan mencemari lingkungan karena bersumber dari air limbah industri tekstil. Lumpur IPAL dikelola oleh dua perusahaan berizin dari Kementerian Lingkungan Hidup dan Kehutanan Republik Indonesia yaitu PT Hijau Lestari dan Prasadha Pamunah Limbah Industri (PT. PPLI) [1]. Lampu TL yang dihasilkan perusahaan ini rate-rata sebanyak 41 buah/bulan. Lampu TL yang berasal dari setiap departemen, limbah lampu ini mengandung merkuri yang dapat membahayakan kesehatan manusia juga dapat meledak jika mengalami perubahan suhu, tekanan atau mengalami oksidasi [11]. Fly ash berasal dari sisa pembakaran batubara di instalasi boiller. Setiap bulan industri ini menghasilkan sebanyak $197 \mathrm{~kg} /$ bulan Fly ash. PT X bekerjasama dengan PT 
Khalda dalam melakukan pengelolaan fly ash. Limbah ini jika tidak dikelola dengan baik akan membahayakan kesehatan apabila terhirup karena mengandung banyak residu bahan kimia seperti silica dan oksida logam berat yang dapat mencemari lingkungan [11]. Oli bekas yang berasal dari operasional PT X sebanyak 50 Liter/bulan. Pihak perusahaan bekerjasama dengan PT Wiraswasta Gemilang Indonesia (PT. WGI) dalam mengelola oli bekas yang dihasilkan dari proses produksi PT X. Oli bekas ini bersifat asam dan korosif, deposit dan logam berat yang bersifat karsinogenik. Oli bekas juga bersifat mudah terbakar jika mengalami perubahan suhu, tekanan atau mengalami oksidasi [11]. Limbah Medis yang berasal dari operasional klinik di PT X terdiri dari plester bekas, kain kassa, kapas bekas, dan jarum suntik dll sebanyak 0,2 kg/bulan. Pihak perusahaan bekerjasama dengan Puskesmas Dayeuhkolot dalam mengelola klinik dan limbah infeksius yang dihasilkan. Dokter dan tenaga medis yang bekerja di klinik perusahaan berasal dari Puskesmas Dayeuhkolot. Petugas Puskesmas melakukan pengecekan pengelolaan LB3 infeksius di perusahaan ini sehingga sesuai dengan persyaratan yang berlaku.

Tabel 2. Jenis, kode, kategori bahaya, dan timbulan LB3 di PT X

\begin{tabular}{lccc}
\hline \multicolumn{1}{c}{ Jenis Limbah } & $\begin{array}{c}\text { Kode } \\
\text { Limbah }^{[2]}\end{array}$ & Karakteristik $^{[2]}$ & Timbulan $^{[1]}$ \\
\hline Lumpur IPAL & $2 / \mathrm{B} 322-3$ & Beracun & $21.490 \mathrm{Kg} / \mathrm{bulan}$ \\
\hline Lampu TL & $2 / \mathrm{B} 107 \mathrm{~d}$ & Beracun & 41 Buah/bulan \\
\hline $\begin{array}{l}\text { Drum bekas bahan pewarna, bahan kimia } \\
\text { untuk proses pengolahan air dan air }\end{array}$ & $2 / \mathrm{B} 104 \mathrm{~d}$ & Beracun & $4 \mathrm{Buah} / \mathrm{bulan}$ \\
limbah & & & \\
\hline Fly Ash yang berasal dari instalasi boiller & 2/B409 & Beracun & $197 \mathrm{Kg} / \mathrm{bulan}$ \\
\hline $\begin{array}{l}\text { Oli bekas yang berasal dari instalasi } \\
\text { boiler, mesin, peralatan transportasi dll }\end{array}$ & 2/B105d & $\begin{array}{c}\text { Mudah Menyala, } \\
\text { korosif }\end{array}$ & 50 Liter/bulan \\
\hline $\begin{array}{l}\text { Reagen yang berasal dari laboratorium, } \\
\text { proses produksi dll }\end{array}$ & 1/A106d & Beracun & 1 Kotak/bulan \\
\hline $\begin{array}{l}\text { Limbah medis yang berasal dari klinik } \\
\text { plester, kain kassa/kapas, dan jarum } \\
\text { suntik bekas) }\end{array}$ & 1/A337-1 & Beracun, infeksius & $0,2 \mathrm{Kg} / \mathrm{bulan}$ \\
\hline
\end{tabular}

\section{Pengemasan dan Pewadahan LB3}

LB3 yang dihasilkan oleh PT X disimpan sementara di TPS khusus LB3 sebelum diserahkan kepada pihak ketiga berizin yaitu PT hijau Lestari, PT PPLI, PT WGI, serta Puskesmas Dayeuhkolot (Profil PT $X, 2019)$. Tempat penyimpanan khusus tersebut dibuat dengan tujuan mencegah pencemaran lingkungan dan mengurangi dampak bahaya terhadap kesehatan manusia yang dapat disebabkan oleh LB3 itu sendiri. Sebelum LB3 dimasukan ke TPS dilakukan pengemasan terlebih dahulu agar tidak mencemari lingkungan, membahayakan manusia dan terjadinya pencampuran limbah dengan jenis berbeda yang dapat menimbulkan hal-hal tertentu. Pengemasan untuk LB3 mengacu Keputusan Kepala Bapedal No 1 tahun 1995. Kemasan yang digunakan untuk mengemas limbah harus sesuai dengan jenis dan karakteristik limbah. Kemasan yang digunakan untuk mengemas lumpur IPAL menggunakan karung, lampu neon dan oli bekas menggunakan drum, reagen bahan kimia menggunakan kotak dari strereoform, limbah medis menggunakan disposal safe.

Berdasarkan hasil pengamatan di lapangan kesesuaian pengemasan yang dilakukan PT X terhadap peraturan disajikan pada Tabel 3. Berdasarkan tabel tersebut terdapat 6 dari 10 parameter yang telah sesuai dengan standar sehingga persentase kesesuaian pengelolaan LB3 dari sistem pengemasan dan Pewadahan LB3 Oli di PT X sebesar 60,0\% dan termasuk ke dalam kategori cukup. 
Tabel 3 Perbandingan Pengemasan dan Pewadahan LB3 Oli di PT X

\begin{tabular}{|c|c|c|c|}
\hline Parameter & $\begin{array}{c}\text { Standar berdasarkan } \\
\text { Kep. Bapedal No 01/1995 }\end{array}$ & Kondisi PT X & Skor \\
\hline Kondisi & $\begin{array}{l}\text { Baik, tidak bocor, tidak berkarat } \\
\text { dan tidak rusak }\end{array}$ & Sudah sesuai & 1 \\
\hline Bahan & $\begin{array}{l}\text { Cocok dengan karakteristik LB3 } \\
\text { yang akan disimpan }\end{array}$ & Sudah sesuai & 1 \\
\hline Keamanan & $\begin{array}{l}\text { Mampu mengamankan limbah } \\
\text { yang ada di dalamnya }\end{array}$ & Sudah sesuai & 1 \\
\hline Penutup & $\begin{array}{l}\text { Kuat untuk mencegah terjadinya } \\
\text { tumpahan saat dilakukan } \\
\text { pemindahan atau pengangkutan }\end{array}$ & Sudah sesuai & 1 \\
\hline Ukuran kemasan & $\begin{array}{l}\text { Berupa drum/tong dengan volume } \\
50,100 \text { atau } 200 \text { liter }\end{array}$ & $\begin{array}{l}\text { Sesuai kemasan menggunakan } \\
\text { drum dengan volume } 200 \text { liter }\end{array}$ & 1 \\
\hline $\begin{array}{l}\text { Karakteristik } \\
\text { pewadahan }\end{array}$ & $\begin{array}{l}\text { Dalam } 1 \text { wadah yang sama } \\
\text { mempunyai karakteristik yang } \\
\text { sama atau cocok }\end{array}$ & Sudah sesuai & 1 \\
\hline Pemeriksaan & $\begin{array}{l}\text { sekurang-kurangnya } 1 \text { minggu } \\
\text { sekali }\end{array}$ & $\begin{array}{l}\text { Belum sesuai karena } \\
\text { pemeriksaan kemasan tidak } \\
\text { dilakukan secara rutin, hanya } \\
\text { dilakukan sekali-sekali }\end{array}$ & 0 \\
\hline Reuse kemasan & $\begin{array}{l}\text { Sama dengan LB3 sebelumnya } \\
\text { atau saling cocok }\end{array}$ & $\begin{array}{l}\text { Perusahaan tidak melakukan } \\
\text { reuse kemasan }\end{array}$ & 0 \\
\hline $\begin{array}{l}\text { Kemasan yang telah } \\
\text { penuh }\end{array}$ & $\begin{array}{l}\text { Kemasan LB3 yang telah terisi } \\
\text { penuh diberi simbol dan label } \\
\text { serta ditutup rapat }\end{array}$ & $\begin{array}{l}\text { Belum sesuai karena tidak } \\
\text { semua kemasan yang telah } \\
\text { penuh dipasangkan simbol } \\
\text { LB3 }\end{array}$ & 0 \\
\hline Kemasan kosong & $\begin{array}{l}\text { Disimpan di TPS B3 jika akan } \\
\text { dipakai kembali dan diberi label } \\
\text { 'KOSONG' }\end{array}$ & $\begin{array}{l}\text { Belum sesuai karena kemasan } \\
\text { kosong tidak disimpan di TPS } \\
\text { melainkan di bengkel dan } \\
\text { tidak terdapat label } \\
\text { 'KOSONG' pada kemasan }\end{array}$ & 0 \\
\hline
\end{tabular}

Angka kesesuaian $=6 / 10 \times 100 \%=60 \%$

Sumber: Hasil Analisis, 2019

Berdasarkan hasil analisis terdapat empat parameter yang harus diperbaiki yaitu pemeriksaan harus dilaksanakan secara rutin sekurang-kurangnya 1 minggu sekali, penggunaan kembali kemasan untuk mengurangi jumlah limbah B3 yang dihasilkan, pemasangan label untuk kemasan yang telah penuh, dan kemasan kosong harus disimpan di TPS dan diberi label.

\section{Penyimpanan LB3}

PT X memiliki Tempat Penyimpanan Sementara (TPS) LB3 dengan luas 480 meter persegi yang dibagi menjadi 3 bagian yaitu tempat penyimpanan lumpur IPAL, tempat penyimpanan oli bekas dan tempat penyimpanan untuk fly ash. Kondisi TPS LB3 di PT X dapat dilihat pada Gambar 1 sampai 4 . Tabel 4. menyajikan hasil analisis untuk TPS LB3. Berdasarkan tabel tersebut 10 dari 14 parameter yang diatur oleh Keputusan Bapedal No 01 tahun 1995 telah sesuai sehingga penilaian TPS LB3 sebesar 71,43\% termasuk ke dalam kategori baik. 


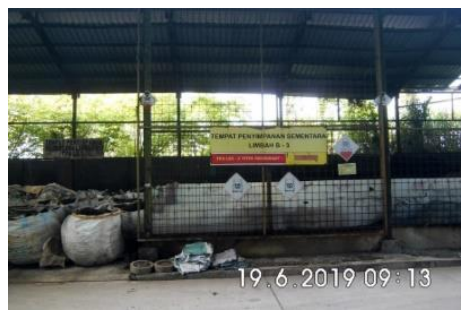

a.

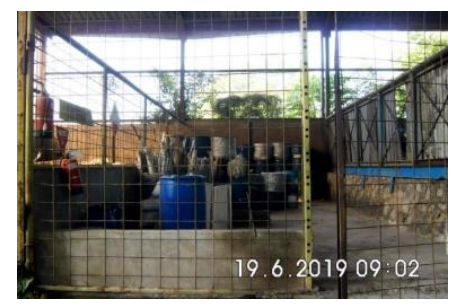

c.

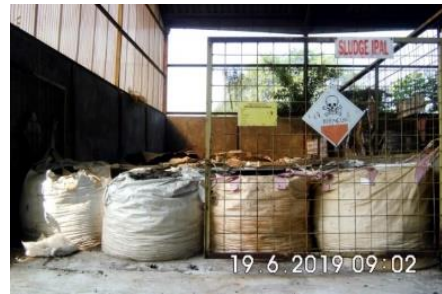

b.

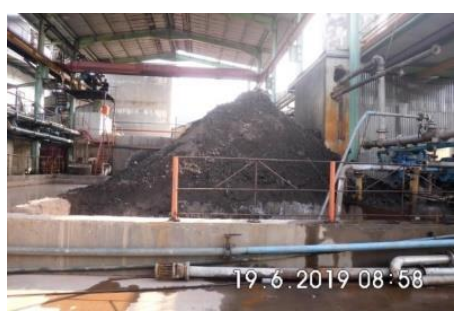

d.

Gambar 1. a. Kondisi TPS LB3, b. Tempat Penyimpanan Lumpur IPAL, c. Tempat Penyimpanan Oli Bekas, Lampu TL, dan d Tempat Penyimpanan Fly Ash di PT X

Tabel 4. Perbandingan TPS B3 di PT X terhadap Peraturan

\begin{tabular}{|c|c|c|c|c|}
\hline No & Parameter & $\begin{array}{c}\text { Standar berdasarkan } \\
\text { Kep. Bapedal No 01/1995 }\end{array}$ & Kondisi PT X & Skor \\
\hline \multicolumn{5}{|c|}{ Tata Cara Penyimpanan LB3 } \\
\hline & Lebar gang & $\begin{array}{l}\text { Lebar gang harus memenuhi } \\
\text { persyaratan untuk manusia } \\
\text { minimal } 60 \mathrm{~cm}\end{array}$ & $\begin{array}{l}\text { Belum sesuai karena tidak } \\
\text { semua bagian TPS } \\
\text { memiliki gang yang dapat } \\
\text { dilalui oleh manusia }\end{array}$ & 0 \\
\hline 2 & Tumpukan Kemasan LB3 & $\begin{array}{l}\text { Penumpukan kemasan LB3 } \\
\text { harus mempertimbangkan } \\
\text { kestabilan tumpukan kemasan, } \\
\text { tumpukan maksimum adalah } 3 \\
\text { lapis dengan dialasi palet }\end{array}$ & $\begin{array}{l}\text { Belum sesuai karena tidak } \\
\text { semua tumpukan kemasan } \\
\text { dialasi dengan palet }\end{array}$ & 0 \\
\hline & Jarak Tumpukan & $\begin{array}{l}\text { Jarak tumpukan tertinggi dan } \\
\text { jarak blok kemasan terluar } \\
\text { terhadap atap dinding bangunan } \\
\text { penyimpanan tidak boleh kurang } \\
\text { dari } 1 \mathrm{~m}\end{array}$ & sudah sesuai & 1 \\
\hline \multicolumn{5}{|c|}{ Persyaratan Bangunan Penyimpanan } \\
\hline & Rancang Bangun & $\begin{array}{l}\text { Memiliki rancang bangun dan } \\
\text { luas ruang penyimpanan yang } \\
\text { sesuai dengan jenis, karakteristik } \\
\text { dan jumlah LB3 yang dihasilkan }\end{array}$ & sudah sesuai & 1 \\
\hline & Terlindungi dari hujan & $\begin{array}{l}\text { Terlindung dari masuknya air } \\
\text { hujan baik secara langsung } \\
\text { maupun tidak langsung }\end{array}$ & sudah sesuai & 1 \\
\hline & Sistem ventilasi & $\begin{array}{l}\text { Dibuat tanpa plafon dan } \\
\text { memiliki sistem ventilasi udara } \\
\text { yang memadai }\end{array}$ & sudah sesuai & 1 \\
\hline & Penerangan & $\begin{array}{l}\text { Memiliki sistem penerangan } \\
\text { (lampu/cahaya matahari) yang } \\
\text { memadai untuk operasional }\end{array}$ & sudah sesuai & 1 \\
\hline & Penangkal petir & $\begin{array}{l}\text { Dilengkapi dengan sistem } \\
\text { penangkal petir }\end{array}$ & $\begin{array}{l}\text { Belum sesuai karena tidak } \\
\text { terdapat penangkal petir }\end{array}$ & 0 \\
\hline
\end{tabular}

Sumber: Hasil Analisis, 2019 
Tabel 4. Perbandingan TPS B3 di PT X terhadap Peraturan (Lanjutan)

\begin{tabular}{|c|c|c|c|c|}
\hline No & Parameter & $\begin{array}{l}\text { Standar berdasarkan } \\
\text { Kep. Bapedal No 01/1995 }\end{array}$ & Kondisi PT X & Skor \\
\hline 9 & Penandaan simbol bangunan & $\begin{array}{l}\text { Pada bagian luar tempat } \\
\text { penyimpanan diberi penandaan } \\
\text { (simbol) }\end{array}$ & sudah sesuai & 1 \\
\hline 10 & Bahan lantai bangunan & $\begin{array}{l}\text { Lantai bangunan penyimpan } \\
\text { harus kedap air, tidak } \\
\text { bergelombang, kuat dan tidak } \\
\text { retak }\end{array}$ & $\begin{array}{l}\text { Belum sesuai karena } \\
\text { bagian lantai TPS } \\
\text { kedap air dan tidak } \\
\text { bergelombang }\end{array}$ & 1 \\
\hline 11 & Pembatas bagian limbah & $\begin{array}{l}\text { Antara bagian penyimpanan } \\
\text { satu dengan lainnya harus } \\
\text { dibuat tanggul atau tembok } \\
\text { pemisah untuk menghindarkan } \\
\text { tercampurnya atau masukya } \\
\text { tumpahan limbah }\end{array}$ & $\begin{array}{l}\text { Terdapat Tembok } \\
\text { Pemisah }\end{array}$ & 1 \\
\hline 12 & Bak penampung limbah & $\begin{array}{l}\text { Harus mempunyai bak } \\
\text { penampung tumpahan LB3 }\end{array}$ & $\begin{array}{l}\text { Terdapat saluran } \\
\text { drainase di bagian luar } \\
\text { TPS }\end{array}$ & 1 \\
\hline 13 & Sarana yang tersedia & $\begin{array}{l}\text { Peralatan dan sistem pemadam, } \\
\text { pagar pengaman, pembangkit } \\
\text { listrik, fasilitas pertolongan } \\
\text { pertama, peralatan komunikasi, } \\
\text { perlengkapan, pintu darurat, } \\
\text { alarm }\end{array}$ & $\begin{array}{l}\text { Belum sesuai karena } \\
\text { hanya terdapat Alat } \\
\text { Pemadam Api Ringan } \\
\text { (APAR) }\end{array}$ & 0 \\
\hline 14 & Lokasi bangunan & $\begin{array}{l}\text { Merupakan Lahan Bebas } \\
\text { Banjir }\end{array}$ & sudah sesuai & 1 \\
\hline \multicolumn{5}{|c|}{ Angka kesesuaian $=10 / 14 \times 100 \%=71,43 \%$} \\
\hline
\end{tabular}

Sumber: Hasil Analisis, 2019

Berdasarkan hasil analisis parameter yang harus diperbaiki yaitu lebar gang menuju TPS Limbah B3 harus memenuhi persyaratan untuk manusia minimal $60 \mathrm{~cm}$, penumpukan kemasan LB3 harus mempertimbangkan kestabilan tumpukan kemasan, tumpukan maksimum adalah 3 lapis dengan dialasi palet, TPS limbah B3 dilengkapi dengan sistem penangkal petir, dan peralatan dan sistem pemadam, pagar pengaman, pembangkit listrik, fasilitas pertolongan pertama, peralatan komunikasi, perlengkapan, pintu darurat, alarm

\section{Pengangkutan LB3}

Berdasarkan PPRI No 101 tahun 2014 pengangkutan LB3 adalah kegiatan pemindahan LB3 dari suatu tempat ke tempat lain dengan menggunakan sarana angkutan, misalnya pemindahan LB3 dari penghasil dan/atau dari pengumpul dan/atau dari pemanfaat dan/atau dari pengolah ke pengumpul dan/atau ke pemanfaat dan/atau ke pengolah dan/atau ke penimbun LB3. Tabel 5. Menyajikan analisis kesesuaian pengelolaan LB3 kegiatan pengangkutan yang dilakukan oleh PT X. Berdasarkan hasil evaluasi kesesuaian kegiatan pengangkutan dengan peraturan mencapai 100\% dan termasuk kategori sangat baik. Semua kegiatan pengangkutan LB3 memenuhi standar yang diatur berdasarkan Keputusan bapedal No 01 tahun 1995. 
Tabel 5. Perbandingan Pengangkutan PT X Terhadap Peraturan

\begin{tabular}{|c|c|c|c|c|}
\hline No & Parameter & $\begin{array}{c}\text { Standar berdasarkan } \\
\text { Kep. Bapedal No 01/1995 }\end{array}$ & Kondisi PT X & Skor \\
\hline 1 & Izin Pengelolaan & $\begin{array}{l}\text { Izin Pengelolaan LB3 untuk } \\
\text { kegiatan Pengangkutan LB3 }\end{array}$ & $\begin{array}{l}\text { Telah sesuai karena PT X telah } \\
\text { bekerjasama dengan pihak ketiga } \\
\text { yang memiliki izin pengangkutan } \\
\text { LB3 }\end{array}$ & 1 \\
\hline 2 & $\begin{array}{l}\text { Dokumen } \\
\text { Pengangkutan }\end{array}$ & $\begin{array}{l}\text { Dokumen pengangkutan LB3 } \\
\text { sebagaimana dimaksud pada } \\
\text { ayat (3) huruf (e) }\end{array}$ & $\begin{array}{l}\text { Telah sesuai karena ketika } \\
\text { melakukan pengangkutan dilakukan } \\
\text { pengecekan berkas agar sesuai } \\
\text { dengan jumlah LB3 yang diangkut }\end{array}$ & 1 \\
\hline 3 & Pelaporan & $\begin{array}{l}\text { Melaporkan pelaksanaan } \\
\text { pengangkutan LB3 }\end{array}$ & $\begin{array}{l}\text { Telah sesuai karena tiap } \\
\text { departemen yang akan melakukan } \\
\text { pengangkutan melaporkan kepada } \\
\text { General Affair (GA), pihak GA } \\
\text { melakukan pelaporan mengenai } \\
\text { pengelolaan LB3 setiap triwulan }\end{array}$ & 1 \\
\hline 4 & $\begin{array}{l}\text { Rekomendasi } \\
\text { pengangkutan } \\
\text { dari K3LH }\end{array}$ & $\begin{array}{l}\text { Pengangkutan LB3 telah } \\
\text { mendapatkan rekomendasi } \\
\text { pengangkutan LB3 dari } \\
\text { K3LH dan izin pengangkutan } \\
\text { LB3 dari kementrian } \\
\text { perhubungan }\end{array}$ & $\begin{array}{l}\text { Telah sesuai karena pihak } \\
\text { pengangkut telah memiliki izin } \\
\text { angkut dari KLHK RI yaitu PT } \\
\text { Hijau Lestari, PT PPLI, PT Khalda, } \\
\text { dan WGI }\end{array}$ & 1 \\
\hline 5 & Jenis Kendaraan & $\begin{array}{l}\text { Kendaraan pengangkut LB3 } \\
\text { yang digunakan sesuai } \\
\text { dengan yang dipersyaratkan }\end{array}$ & Telah sesuai & 1 \\
\hline 6 & Jenis Limbah & $\begin{array}{l}\text { Jenis LB3 yang diangkut } \\
\text { sesuai dengan rekomendasi } \\
\text { dan izin pengangkutan LB3 }\end{array}$ & $\begin{array}{l}\text { Telah sesuai karena jenis limbah } \\
\text { yang diangkut telah sesuai dengan } \\
\text { izin }\end{array}$ & 1 \\
\hline \multicolumn{5}{|c|}{ Ketentuan Berdasarkan Kep. Bapedal No. 2 Tahun 1995} \\
\hline 7 & Manifest & $\begin{array}{l}\text { Lembar ketiga atau salinan } \\
\text { disimpan oleh penghasil LB3 }\end{array}$ & $\begin{array}{l}\text { Telah sesuai karena PT X sudah } \\
\text { memiliki salinan ketiga dalam } \\
\text { pengangkutan }\end{array}$ & 1 \\
\hline
\end{tabular}

Angka kesesuaian $=7 / 7 \times 100 \%=100 \%$

Sumber: Hasil Analisis, 2019

\section{Pelekatan Simbol dan Label B3}

Berdasarkan PPRI No.101 tahun 2014, kemasan LB3 wajib dilekati simbol LB3. Pemberian simbol dan label PT X mengacu pada regulasi yang telah ditetapkan pemerintah tentang simbol dan label LB3. Tabel 6 menyajikan analisis kesesuaian pelekatan simbol LB3 PT X terhadap peraturan yang berlaku.

Berdasarkan Tabel 6 tingkat kesesuaian pelekatan simbol dan label LB3 di PT X terhadap peraturan terkait adalah sebesar 50\% termasuk kategori cukup. Berdasarkan analisisi 6 dari 12 parameter yang diatur belum memenuhi syarat yang ditentukan. Upaya yang harus ditingkatkan dalam pelekatan simbol dan label limbah B3 yaitu: meletakan simbol sesuai karakteristik, kemasan tempat penyimpanan dan alat angkut harus disertai simbol, memberikan informasi dalam label secara lengkap, label dan simbol dipasang disisi kemasan sehingga mudah dilihat, simbol dan label terpasang sempurna tidak lepas/terlepas/diganti sebelum kemasan kosong dibersihkan, dan label penunjuk tutup kemasan ukurannya harus sesuai dengan aturan yaitu $15 \times 7 \mathrm{~cm}$ 
Tabel 6 Perbandingan Pelekatan Simbol LB3 di PT X

\begin{tabular}{|c|c|c|c|c|}
\hline No & Parameter & $\begin{array}{c}\text { Standar berdasarkan } \\
\text { Kep. Bapedal No 01/1995 }\end{array}$ & Kondisi PT X & Skor \\
\hline 1 & Bentuk & $\begin{array}{l}\text { Bujur sangkar yang diputar } 45 \\
\text { derajat dengan sisi dalam } 95 \% \\
\text { ukuran }\end{array}$ & Sudah sesuai & 1 \\
\hline \multirow[t]{2}{*}{2} & \multirow[t]{2}{*}{ Ukuran } & Kemasan minimal $10 \mathrm{~cm} \mathrm{x} 10 \mathrm{~cm}$ & Sudah sesuai & 1 \\
\hline & & Tempat minimal $25 \mathrm{~cm} \mathrm{x} 25 \mathrm{~cm}$ & Sudah sesuai & 1 \\
\hline 3 & Bahan Label & Tahan Goresan dan zat kimia & Sudah sesuai & 1 \\
\hline \multirow[t]{6}{*}{4} & \multirow[t]{6}{*}{ Pemasangan } & $\begin{array}{l}\text { Meletakan simbol sesuai } \\
\text { karakteristik }\end{array}$ & $\begin{array}{l}\text { Belum sesuai karena ada } \\
\text { beberapa LB3 yang tidak } \\
\text { terdapat simbol }\end{array}$ & 0 \\
\hline & & $\begin{array}{l}\text { Kemasan tempat penyimpanan dan } \\
\text { alat angkut harus disertai simbol }\end{array}$ & $\begin{array}{l}\text { Belum sesuai karena alat angkut } \\
\text { tidak disertai simbol }\end{array}$ & 0 \\
\hline & & $\begin{array}{l}\text { Informasi dalam label harus } \\
\text { lengkap }\end{array}$ & $\begin{array}{l}\text { Belum sesuai karena keterangan } \\
\text { LB3 pada label tidak diisi } \\
\text { dengan jelas }\end{array}$ & 0 \\
\hline & & Melekat kuat pada kemasan & Sudah sesuai & 1 \\
\hline & & $\begin{array}{l}\text { Dipasang disisi kemasan yang } \\
\text { mudah dilihat }\end{array}$ & $\begin{array}{l}\text { Belum sesuai karena beberapa } \\
\text { tidak terdapat label dan beberapa } \\
\text { label yang dipasang tertutup }\end{array}$ & 0 \\
\hline & & $\begin{array}{l}\text { simbol dan Label tidak } \\
\text { lepas/terlepas/diganti sebelum } \\
\text { kemasan kosong dibersihkan }\end{array}$ & $\begin{array}{l}\text { Belum sesuai karena beberapa } \\
\text { LB3 tidak menggunakan simbol } \\
\text { dan label }\end{array}$ & 0 \\
\hline \multirow[t]{2}{*}{5} & \multirow{2}{*}{$\begin{array}{l}\text { Ukuran } \\
\text { Label }\end{array}$} & Ukuran label minimal $20 \times 15 \mathrm{~cm}$ & Sudah sesuai & 1 \\
\hline & & $\begin{array}{l}\text { Label penunjuk tutup kemasan } \\
\text { ukuran } 15 \mathrm{~cm} \times 7 \mathrm{~cm}\end{array}$ & $\begin{array}{l}\text { Belum sesuai karena beberapa } \\
\text { tutup kemasan tidak disertai } \\
\text { label }\end{array}$ & 0 \\
\hline
\end{tabular}

Sumber: Hasil Analisis, 2019

\section{Rekapitulasi Evaluasi Pengelolaan LB3 di PT X}

Berdasarkan hasil pengamatan PT X telah melakukan pengelolaan LB3 dengan baik karena telah mengikuti aturan yang berlaku mengenai pengelolaan LB3. Akan tetapi masih perlu adanya peningkatan dan perbaikan pengelolaan LB3 di perusahaan. Untuk mengetahui kesesuaian dari pengelolaan LB3 di PT X dapat di lihat pada Tabel 7 mengenai rekapitulasi hasil pengelolaan LB3.

Tabel 7. Rekapitulasi Hasil Pengelolaan LB3 di PT X

\begin{tabular}{clcc}
\hline No & Hasil Evaluasi Pengelolaan LB3 & Skor $(\boldsymbol{\%})$ & Ketercapaian \\
\hline 1 & Pengemasan & 60,00 & Cukup \\
\hline 2 & Penyimpanan & 71,43 & Baik \\
\hline 3 & Pengangkutan & 100,00 & Baik \\
\hline 4 & Pelekatan simbol dan label & 50,00 & Cukup \\
\hline Rata-rata & & 70,36 & Baik \\
\hline
\end{tabular}

(Sumber: Hasil Analisis, 2019)

Berdasarkan hasil analisis yang tertuang dalam Tabel 7 secara keseluruhan pengelolaan LB3 di PT X termasuk kategori baik dengan nilai kesesuaian sebesar 72,36\%. Langkah untuk memperbaiki kinerja pengelolaan LB3 maka yang harus dilakukan yaitu memperbaiki proses pelekatan simbol dan label yang masih memiliki nilai rendah yaitu 50\%, selanjutnya proses pengemasan LB3 yang masih bernilai $60 \%$ dan penyimpanan dengan nilai kesesuaian mencapai $71,43 \%$. Upaya peningkatan kesesuaian pengelolaan LB3 di perusahaan ini dengan peraturan yang berlaku meliputi tiga kegiatan yaitu:

1. Kegiatan pengemasan dan pewadahan LB3 Oli di PT X, perbaikan yang harus dilakukan yaitu: (1) harus melakukan pemeriksaan sekurang-kurangnya 1 minggu sekali, (2) kemasan harus melakukan 
penggunakan kembali (reuse) kemasan, (3) kemasan LB3 yang telah terisi penuh diberi simbol dan label serta ditutup rapat, dan (4) kemasan kosong harus disimpan di TPS B3 jika akan dipakai kembali dan diberi label 'KOSONG'

2. Kegiatan penyimpanan sementara di TPS LB3, perbaikan yang harus dilakukan yaitu: (1) lebar gang harus memenuhi persyaratan untuk manusia minimal $60 \mathrm{~cm}$, (2) penumpukan kemasan LB3 harus mempertimbangkan kestabilan tumpukan kemasan, tumpukan maksimum adalah 3 lapis dengan dialasi palet, (3) TPS LB3 dilengkapi dengan sistem penangkal petir, (4) harus tersedia peralatan dan sistem pemadam, pagar pengaman, pembangkit listrik, fasilitas pertolongan pertama, peralatan komunikasi, perlengkapan, pintu darurat, alarm.

3. Pelekatan Simbol LB3, perbaikan yang harus dilakukan meliputi: (1) pemasangan simbol harus sesuai dengan karakteristik LB3, (2) kemasan tempat penyimpanan dan alat angkut harus disertai simbol, (3) Informasi dalam label harus lengkap, (4) simbol harus dipasang disisi kemasan yang mudah dilihat, (5) simbol dan Label tidak lepas/terlepas/diganti sebelum kemasan kosong dibersihkan, dan (6) label penunjuk tutup kemasan ukuran 15 x $7 \mathrm{~cm}$.

\section{KESIMPULAN}

Berdasarkan hasil evaluasi mengenai pengelolaan LB3 yang dilakukan oleh PT X dapat disimpulkan beberapa hal yaitu sumber LB3 berasal dari proses produksi, lumpur IPAL, fly ash dari proses pembakaran boiler, labolatorium, pemeliharaan mesin, dan klinik. Jenis LB3 yang dihasilkan berasal dari sumber spesifik umum yaitu lumpur IPAL dan limbah medis, sumber spesifik khusus yaitu hanya fly ash dan sumber tidak spesifik yang meliputi lampu TL, drum bekas LB3, oli bekas dan reagen. Karakteristik LB3 yang dihasilkan industri ini bersifat beracun, mudah menyala, korosif dan infeksius. PT X telah melakukan pengelolaan LB3 yang meliputi aspek pengemasan dan pewadahan, pengumpulan, penyimpanan, pengangkutan dokumen pengelolaan LB3, dan pelabelan LB3. Kegiatan pengangkutan PT X bekerja sama dengan pihak ketiga diantaranya adalah PT Hijau Lestari, PT PPLI, PT Khalda, dan WGI. Berdasarkan hasil analisis ketercapaian pengelolaan LB3 di perusahaan ini sebesar 72,36\% termasuk kategori baik. Upaya pengelolaan LB3 yang harus ditingkatkan yaitu pada proses pengemasan, pewadahan, penyimpanan di TPS, dan pelekatan simbol dan label, LB3.

\section{DAFTAR PUSTAKA}

[1] Anonim (2019). Laporan Profil Kinerja Perusahaan. PT. X. Kabupaten Bandung Jawa Barat

[2] Kementerian Lingkungan Hidup Indonesia (2014). Peraturan Pemerintah Republik Indonesia Nomor 101 Tahun 2014 mengenai Pengelolaan Limbah Bahan Berbahaya dan Beracun. Jakarta Indonesia

[3] Kementerian Lingkungan Hidup Indonesia (2013). Peraturan Menteri Lingkungan Hidup Republik Indonesia Nomor 14 tahun 2013 mengenai Simbol dan Label Limbah Bahan Berbahaya dan Beracun". Jakarta Indonesia

[4] Badan Pengendalian Lingkungan Hidup Indonesia (1995). "Keputusan Kepala Bapedal No.1 tahun 1995 mengenai Tata Cara dan Persyaratan Teknis Penyimpanan dan Pengumpulan Limbah Bahan Berbahaya dan Beracun". Jakarta Indonesia

[5] Badan Pengendalian Lingkungan Hidup Indonesia (1995). "Keputusan Bapedal No. 2 Tahun 1995 tentang dokumen Limbah Bahan Berbahaya dan Beracun". Jakarta Indonesia

[6] Suharsimi Arikunto, (2008). "Prosedur penelitian Suatu pendekatan Praktik". Rineka karya Jakarta Indonesia

[7] Siti Amalia Fajriyah dan Eka Wardhani (2020). "Evaluasi Pengelolaan Limbah Bahan Berbahaya dan Beracun (B3) di PT. X”. Jurnal Serambi Engineering, Volume V, No. 1 Januari 2020 hal 711719

[8] Salma Savira Siddik dan Eka Wardhani (2020). "Pengelolaan Limbah B3 Di Rumah Sakit X Kota Batam”. Jurnal Serambi Engineering, Volume V, No. 1 Januari 2020 hal 760-767

[9] Muhammad Afrizal Nandito (2018). "Identifikasi Pengelolaan LB3 Padat Klinik Gigi di Kota Yogyakarta". Skripsi Jurusan Teknik Lingkungan Universitas Islam Indonesia. Jogyakarta Indonesia 
[10] Miflathul Jannah,. (2018). Tugas Akhir Studi Tentang Pengelolaan Bahan Berbahaya dan Beracun (B3) di PT Indopherin Jaya Probolinggo Tahun 2018. Politeknik Kesehatan Kemenkes Surabaya Jurusan Kesehatan Lingkungan Kesehatan Lingkungan: Surabaya Indonesia

[11] Palar. H. (1994). Pencemaran dan Toksikologi logam berat. Jakarta: Rineka Cipta. 